\title{
SELEKSI UNIT PENANGKAPAN IKAN TEPAT GUNA DI PULAU ENGGANO, PROVINSI BENGKULU
}

\author{
Selection of Appropriate Fisheries Unit in Enggano Island, Province of Bengkulu \\ Oleh: \\ Ully Wulandari ${ }^{*}$, Domu Simbolon ${ }^{2}$, Ronny I Wahju² \\ ${ }^{1}$ Mahasiswa Program Pascasarjana Departemen PSP FPIK IPB \\ ${ }^{2}$ Departemen PSP FPIK IPB \\ *Korespondensi: ulegbulu@gmail.com
}

\begin{abstract}
ABSTRAK
Penelitian ini bertujuan untuk menyeleksi dan menentukan unit penangkapan ikan yang tepat guna di Perairan Pulau Enggano Provinsi Bengkulu. Penelitian dilakukan di Desa Kahyapu yang merupakan desa penghasil ikan terbesar di Pulau Enggano. Nelayan lokal menggunakan alat tangkap tradisional, namun hasil tangkapan yang diperoleh tetap maksimal. Hal tersebut mengindikasikan adanya potensi yang bisa digali lebih dalam untuk kesejahteraan masyarakat di pulau terluar dan terpencil di Provinsi Bengkulu. Pulau Enggano juga telah dicadangkan sebagai Kawasan Konservasi Perairan Daerah (KKPD) oleh Pemerintah Bengkulu Utara. Hal inilah yang menjadi latar belakang penelitian, supaya aktivitas ekonomi masyarakat dari kegiatan perikanan tangkap dan upaya pelestarian yang dilakukan oleh pemerintah Bengkulu Utara dapat berjalan tanpa tumpang tindih. Penelitian dilakukan dengan melakukan Multiple Criteria Analysis (MCA) terhadap aspek biologi, teknologi, sosial dan ekonomi dari dua jenis alat tangkap yang digunakan oleh nelayan Desa Kahyapu, yaitu gillnet dan rawai. Hasil penelitian menunjukkan bahwa unit penangkapan ikan tepat guna yang memiliki urutan prioritas utama adalah rawai yang unggul dalam ke-empat aspek pengamatan. Rawai secara finansial dan benefit memberikan nilai yang lebih tinggi bila dibandingkan dengan gillnet. Hasil analisis MCA untuk standarisasi $\mathrm{B} / \mathrm{C}$ ratio dari alat tangkap rawai adalah 0,49 sedangkan gillnet adalah 0,34 . Nilai $\mathrm{R} / \mathrm{C}$ ratio alat tangkap rawai yang telah distandarisasi menggunakan analisis MCA adalah 0,51 sedangkan gillnet adalah 0,33.
\end{abstract}

Kata kunci: gillnet, multi kriteria analisis, pulau enggano, rawai, seleksi unit penangkapan ikan

\begin{abstract}
This research aims to select and determine the unit appropriate fishing in the Enggano waters of Bengkulu Province. This research conducted in the village of Kahyapu as the largest fish-producing village on the Enggano Island. Local fishermen using traditional capture tool, but the catch is obtained fixed maximum. It indicates a potential which could be dug deeper for the well-being of the communities in remote and outlying islands in the province of Bengkulu. Enggano island has also been proposed as a conservation area regional waters (KKPD) by the Government of North Bengkulu. This became the background research, that the economic activity of the community activities of fisheries catch and preservation efforts undertaken by the Government can walk without overlap. Research done by performing Multiple Criteria Analysis (MCA) towards aspects of biology, technology, social and economic of the two types of capture tool which is used by fishermen of the village of Kahyapu, i.e., the gillnet and rawai. The results showed that appropriate fisheries unit which has the order of priority is superior in rawai to the four aspects of the observations. Rawai benefit financially and provide higher value when compared to gillnet. The results of the analysis of the MCA for Standardization of $B / C$ ratio from the capture tool rawai is 0.49 whereas gillnet is 0.34 . The value of
\end{abstract}


$R / C$ ratio capture tool that has been standardized using rawai analysis $M C A$ is 0.51 whereas gillnet was 0.33 .

Keywords. gillnet, multiple criteria analysis, enggano island, rawai, catching fish unit selection

\section{PENDAHULUAN}

Letak geografis Desa Kahyapu yang berada dibagian wilayah pesisir membuat masyarakat Desa Kahyapu pada umumnya menggerakkan perekonomian dari usaha perikanan tangkap. Dinas Kelautan dan Perikanan Bengkulu Utara (2013) mengelompokkan lima jenis sumberdaya ikan yang terdapat di Perairan Pulau Enggano, yaitu ikan pelagis besar, ikan pelagis kecil, ikan demersal, udang, dan ikan karang. Untuk melakukan penangkapan ikan, para nelayan lokal menggunakan armada perahu dengan motor tempel. Alat tangkap yang banyak digunakan adalah jaring insang permukaan (surface gillnet) dan pancing rawai.

Posisi geografis Pulau Enggano yang jauh dari Kota Bengkulu membuat kondisi pulau tersebut menjadi berbeda dari segi ekonomi dan sosial. Kebutuhan ekonomi di pulau tersebut lebih tinggi, sebab akses untuk mendapatkan segala kebutuhan sehari-hari menjadi lebih sulit. Harga bahan bakar hingga kebutuhan pokok sehari-hari di Pulau Enggano menjadi dua hingga tiga kali lipat dari harga normal. Perputaran ekonomi di Pulau Enggano yang bergerak lebih banyak dari usaha perikanan tangkap, membuat nelayan lokal harus mendapatkan hasil tangkapan yang memadai untuk kebutuhan sehari-hari. Namun pemerintah setempat mencadangkan Pulau Enggano sebagai Kawasan Konservasi Perairan Daerah (KKPD) agar sumberdaya perikanan dan hayati di pulau tersebut tetap terjaga.

Penelitian ini bertujuan untuk menentukan unit penangkapan ikan yang tepat guna bagi nelayan di Desa Kahyapu Pulau Enggano. Hal ini menjadi penting untuk dilakukan, supaya nelayan lokal bisa mempertimbangkan unit penangkapan ikan yang tepat guna untuk meningkatkan pendapatan dari hasil tangkapan dengan alat tangkap yang ekonomis. Selain itu, juga bermanfaat untuk mencegah terjadinya penggunaan alat penangkapan ikan yang tidak tepat guna sehingga berpotensi membahayakan sumberdaya pesisir yang ada. Salah satu upaya yang dapat dilakukan untuk mendukung tujuan tersebut di atas adalah menganalisis karakteristik alat penangkapan ikan di Kecamatan Enggano, Bengkulu Utara. Hal tersebut menjadi perlu dikaji secara mendalam dan sistematis agar diperoleh informasi yang akurat dan dapat menjadi bahan pertimbangan dalam penggunaan teknologi penangkapan ikan yang tepat guna.

\section{METODE PENELITIAN}

\section{Waktu dan Lokasi Penelitian}

Penelitian dilakukan di Desa Kahyapu Kecamatan Enggano (Gambar 1), Kabupaten Bengkulu Utara pada bulan Juli-September 2016. Lokasi penelitian dipilih karena merupakan salah satu lokasi yang memiliki jumlah nelayan terbanyak dan juga daerah tersebut ditetapkan sebagai pencadangan kawasan konservasi perairan daerah.

\section{Peralatan Penelitian}

Peralatan yang digunakan dalam penelitian ini meliputi:

1. Data sheet dan alat tulis, untuk mencatat setiap hasil wawancara;

2. Kamera, untuk mengambil foto setiap kegiatan dalam penelitian;

3. Kuisioner, untuk memandu berjalannya wawancara yang dilakukan di lapangan terhadap para nelayan;

4. Hardware dan software, untuk menginput, menyimpan dan mengolah data.

\section{Metode Pengumpulan Data}

Pengumpulan data primer dilakukan secara purposive sampling dengan melakukan survey dan wawancara terhadap nelayan di Desa Kahyapu. Dahlan (2015) mengatakan bahwa pemilihan sekelompok subjek dalam purposive sampling didasarkan atas ciri-ciri 


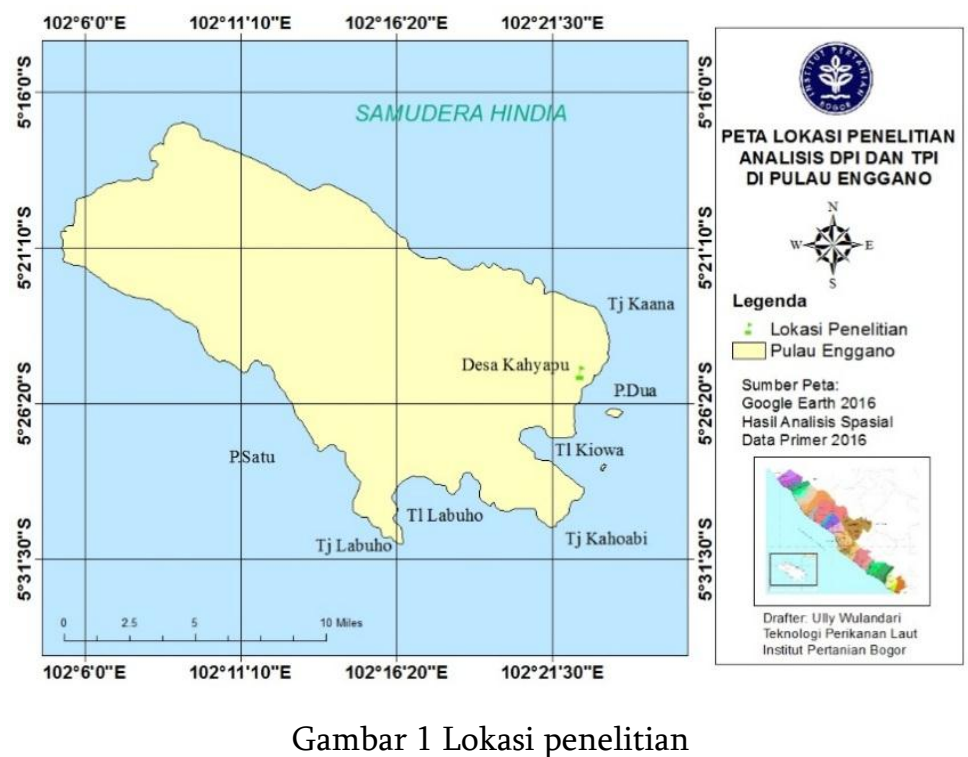

tertentu yang dipandang mempunyai sangkut paut yang erat dengan ciri-ciri populasi yang sudah diketahui sebelumnya, dengan kata lain unit sampel yang dihubungi disesuaikan dengan kriteria-kriteria tertentu yang diterapkan berdasarkan tujuan penelitian.

Pemilihan sampel unit penangkapan ikan dilakukan secara purposive sampling dengan terlebih dahulu mengidentifikasi jenis unit penangkap ikan yang beroperasi. Masingmasing sub populasi ditentukan sampel armada sebanyak 50\% untuk diamati (Arikunto, 2006). Dasar pertimbangan dalam penentuan sampel armada dengan cara purposive sampling ini adalah:

1. Unit Penangkap Ikan yang terdiri dari kapal, alat tangkap dan nelayan yang beroperasi di lokasi penelitian

2. Kapal layak beroperasi

3. Pemilik kapal memberi izin untuk dilakukan pengambilan data penelitian

4. Anak Buah Kapal (ABK) dari sampel kapal terpilih dapat memberikan informasi yang representatif dan komprehensif sesuai dengan kebutuhan penelitian

Data yang akan dikumpulkan dari masingmasing sampel armada adalah:

1. Data jumlah dan jenis hasil tangkapan

2. Ukuran panjang ikan yang dominan tertangkap

3. Jumlah trip

4. Jenis-jenis alat tangkap yang digunakan
5. Metode pengoperasian/alat

6. Pengaruh pengoperasian/alat terhadap lingkungan

7. Penggunaan teknologi/alat

8. Hasil tangkapan/bahan bakar

9. Jalur penangkapan

10. Jumlah tenaga kerja/alat

11. Upah rata-rata tenaga kerja/alat

12. Peluang terjadinya konflik

13. Modal investasi/alat

14. Biaya operasional/alat

15. Harga dan pemasaran hasil tangkapan

16. Pemeliharaan kapal dan alat tangkap ikan

Pengambilan data primer tersebut akan dilakukan dengan metode survey dan wawancara dengan mengikuti setidaknya satu trip penangkapan secara langsung yang dilakukan oleh kapal sampel. Metode survey ini merupakan suatu metode yang dilakukan untuk mendapatkan atau memperoleh faktafakta dari gejala yang ada dan mencari keterangan secara faktual (Nazir 2003). Selain itu, untuk mendapatkan seluruh data primer yang dibutuhkan dalam penelitian ini maka dilakukan wawancara dan pengisian kuisioner oleh responden. Responden dipilih secara purposive sampling, yaitu nelayan pada kapal sampel penelitian sebanyak 2 orang dari masing-masing kapal yakni juru mudi dan ABK kapal.

Pengumpulan data sekunder diperoleh dari Dinas Kelautan dan Perikanan, Kantor Kecamatan serta data hasil penelitian 
sebelumnya. Data yang dikumpulkan mencakup kondisi geografi dan administrasi wilaya, serta data mengenai ekosistem dan ekologi di Perairan Enggano.

\section{Analisis Data}

\section{A. Aspek Biologi}

Analisis terhadap aspek biologi dilakukan untuk melihat apakah jenis alat tangkap yang digunakan merusak sumberdaya yang ada atau tidak. Penilaian aspek biologi unit penangkapan ikan dititik beratkan pada tiga kriteria yaitu produktivitas, komposisi jenis hasil tangkapan, dan ukuran panjang ikan yang dominan tertangkap untuk masingmasing alat tangkap. Kriteria penilaian didasarkan kepada hasil pengamatan dan pengukuran secara langsung dari hasil tangkapan armada sampel.

Kriteria pertama yang dijadikan bahan penilaian aspek biologi adalah produktivitas. Prioritas masing-masing unit penangkapan ikan pelagis kecil ditentukan berdasarkan nilai produktivitas tertinggi, semakin tinggi produktivitas maka prioritasnya semakin besar. Kriteria kedua adalah komposisi jenis hasil tangkapan setiap unit penangkapan. Prioritas ditentukan berdasarkan jumlah komposisi jenis hasil tangkapan, semakin beragam jenis ikan yang tertangkap oleh alat tangkap maka nilai prioritasnya semakin buruk. Hal ini terkait dengan tingkat selektivitas unit penangkapan ikan, karena semakin sedikit jumlah komposisi jenis ikan yang tertangkap maka tingkat selektivitas alat tinggi. Sebaliknya, bila jumlah komposisi jenis hasil tangkapan semakin banyak maka selektivitas alat rendah.
Kriteria terakhir dari penilaian aspek biologi adalah ukuran hasil tangkapan. Ukuran panjang ikan diperoleh dengan mengukur dari ujung mulut sampai ujung sirip ekor (Suwarni 2009). Ukuran panjang ikan diukur hanya untuk jenis ikan yang dominan tertangkap, diambil sebanyak $10 \%$ dari hasil tangkapan armada sampel. Selanjutnya dibandingkan dengan ukuran Lenght at first maturity (Lm) atau ukuran matang gonad jenis ikan dominan tersebut. Ukuran $\mathrm{Lm}$ diperoleh melalui literatur hasil penelitian terdahulu yang dilakukan pada wilayah perairan yang sama atau wilayah perairan yang beriklim tropis.

Selanjutnya hasil perbandingan antara ukuran ikan sampel dengan Lm digunakan untuk menentukan kategori ikan termasuk layak tangkap atau tidak layak tangkap (Simbolon 2004). Ikan yang layak tangkap merupakan ikan-ikan yang ukurannya lebih besar dari ukuran ikan yang pertama kali matang gonad atau length at first maturity (LM). Ikan-ikan yang belum layak tangkap merupakan ikan-ikan yang ukurannya lebih kecil dari LM (Wujdi et al. 2013). Penilaian terhadap ketiga kriteria tersebut dapat dilihat pada tabel 1.

\section{B. Aspek Teknis}

Analisis ini dilakukan untuk mengetahui tingkat efektivitas alat tangkap yang digunakan pada armada sampel (gillnet, pancing dan bubu). Kriteria teknis yang digunakan meliputi metode pengoperasian alat tangkap, pengaruh pengoperasian alat tangkap terhadap lingkungan, hasil tangkapan terhadap bahan bakar, jalur penangkapan, penggunaan teknologi, dan bycatch. Penilaian dilakukan

Tabel 1 Kriteria. bobot dan skor zona potensial penangkapan ikan

\begin{tabular}{|c|c|}
\hline Kriteria & Skor \\
\hline \multirow[t]{2}{*}{ Produktivitas } & $\begin{array}{l}1 \text { rendah (Produktivitas rata-rata }>\text { Produktivitas } \\
\text { penangkapan di DPI tersebut) }\end{array}$ \\
\hline & $\begin{array}{l}2 \text { tinggi (Produktivitas rata-rata }<\text { Produktivitas } \\
\text { penangkapan di DPI tersebut) }\end{array}$ \\
\hline \multirow{2}{*}{$\begin{array}{l}\text { Komposisi jenis hasil } \\
\text { tangkapan }\end{array}$} & 1 tinggi (hasil tangkapan $>5$ jenis) \\
\hline & 2 rendah (hasil tangkapan $<5$ jenis) \\
\hline \multirow[t]{2}{*}{ Ukuran ikan } & 1 tidak layak tangkap (ukuran ikan $<$ Lm) \\
\hline & 2 layak tangkap (ukuran ikan > Lm) \\
\hline
\end{tabular}


Tabel 2 Kriteria dan skor aspek teknis

\begin{tabular}{|c|c|}
\hline Kriteria & Skor \\
\hline \multirow{2}{*}{$\begin{array}{l}\text { Metode pengoperasian alat } \\
\text { tangkap }\end{array}$} & 1 sulit (memerlukan keahlian dan sertifikat khusus) \\
\hline & 2 mudah (memerlukan keahlian dan sertifikat khusus) \\
\hline \multirow[t]{2}{*}{$\begin{array}{l}\text { Pengaruh pengoperasian } \\
\text { alat terhadap lingkungan }\end{array}$} & $\begin{array}{l}1 \text { berpengaruh (menggerus dasar perairan dan merusak } \\
\text { karang) }\end{array}$ \\
\hline & $\begin{array}{l}2 \text { tidak berpengaruh (tidak menggerus dasar perairan dan } \\
\text { merusak karang) }\end{array}$ \\
\hline \multirow{2}{*}{$\begin{array}{l}\text { Hasil tangkapan terhadap } \\
\text { bahan bakar (bensin/solar) }\end{array}$} & 1 rendah (hasil tangkapan $\leq$ modal bahan bakar) \\
\hline & 2 tinggi ( hasil tangkapan > modal bahan bakar) \\
\hline \multirow[t]{2}{*}{ Jalur penangkapan ikan } & $\begin{array}{l}1 \text { tidak sesuai (gillnet mesh size }>1,5 \text { inch, } \mathrm{P}>500 \mathrm{~m}, \mathrm{GT} \\
>10 \text { di jalur IB, II, III bubu jumlah }>300 \text { di jalur IA, IB, } \\
\text { II }\end{array}$ \\
\hline & $\begin{array}{l}2 \text { sesuai (gillnet mesh size } 1,5 \text { inch, } \mathrm{P} \leq 500 \mathrm{~m}, \mathrm{GT} \leq 10 \\
\text { jalur IB, II, III bubu jumlah } \leq 300 \text { jalur } 1 \mathrm{~A}, 1 \mathrm{~B} \text {, II pancing } \\
\text { di semua jalur) }\end{array}$ \\
\hline \multirow{2}{*}{$\begin{array}{l}\text { Tingkat penggunaan } \\
\text { teknologi }\end{array}$} & 1 rendah $($ mesin $<15 \mathrm{PK})$ \\
\hline & 2 tinggi $($ mesin $>15 \mathrm{PK})$ \\
\hline \multirow[t]{2}{*}{ Bycatch } & 1 tinggi (jumlah hasil tangkapan sampingan $\geq 60 \%$ ) \\
\hline & 2 rendah (jumlah hasil tangkapan sampingan $\leq 60 \%$ ) \\
\hline
\end{tabular}

dengan cara skoring dengan rentang skor 1 hingga 2 untuk semua kriteria. Kriteria penilaian didasarkan kepada hasil pengisian kuisioner dan wawancara dengan responden. Penilaian disajikan pada Tabel 2.

C. Aspek Sosial

Analisis sosial ditinjau dari penerimaan masyarakat terhadap alat tangkap yang digunakan, dapat memberikan kesempatan kerja kepada nelayan setempat atau tidak, serta peluang terjadinya konflik antar nelayan yang berbeda alat tangkap. Penilaian dilakukan dengan cara skoring dari pengisian kuisioner. Rentang nilai yang digunakan adalah 1 dan 2 untuk semua kriteria. Penilaian disajikan pada Tabel 3.

D. Aspek Ekonomi

Analisis yang digunakan untuk menentukan teknologi penangkapan ikan yang tepat guna di Perairan Enggano berdasarkan aspek ekonomi dilihat dari beberapa kriteria yang dianggap penting untuk membedakan alat tangkap gillnet dan rawai, yaitu:

1. Modal investasi, yakni biaya yang dikeluarkan oleh investor untuk membeli barang-barang yang diperlukan dalam melaksanakan suatu

Tabel 3 Kriteria dan skor aspek sosial

\begin{tabular}{|c|c|}
\hline Kriteria & Skor \\
\hline \multirow[t]{2}{*}{$\begin{array}{l}\text { Penerimaan masyarakat terhadap alat } \\
\text { tangkap yang digunakan }\end{array}$} & $\begin{array}{l}1 \text { - rendah (persentase alat tangkap yang } \\
\text { digunakan responden }<60 \% \text { ) }\end{array}$ \\
\hline & $\begin{array}{l}2 \text { - tinggi (persentase alat tangkap yang } \\
\text { digunakan responden }>60 \% \text { ) }\end{array}$ \\
\hline \multirow[t]{2}{*}{ Membuka lapangan pekerjaan } & $1-($ tidak $)$ \\
\hline & 2 - (iya) \\
\hline \multirow[t]{2}{*}{ Menimbulkan terjadinya konflik } & 1 - (ada) \\
\hline & 2 - (tidak ada) \\
\hline \multirow[t]{2}{*}{ Kearifan lokal } & 1 - (tidak ada) \\
\hline & 2 - (ada) \\
\hline
\end{tabular}


unit usaha. Modal investasi yang diperlukan untuk melaksanakan usaha penangkapan ikan di Perairan Enggano dengan 3 jenis alat tangkap (gillnet, pancing dan bubu) diasumsikan memiliki nilai yang berbeda. Penentuan teknologi penangkapan ikan tepat guna dengan menggunakan nilai investasi didasarkan pada nilai investasi terendah. Dengan demikian unit penangkapan yang memberikan nilai investasi terendah merupakan unit penangkapan yang terbaik.

2. Biaya usaha, merupakan pengeluaran usaha yang digunakan untuk keperluan kegiatan penangkapan ikan. Biaya ini terbagi menjadi dua yaitu biaya tetap dan biaya variabel. Biaya tetap adalah biaya yang jumlahnya tetap tidak tergantung pada perubahan tingkat kegiatan dalam menghasilkan tingkat pengeluaran atau produk dalam interval waktu tertentu. Biaya tersebut harus tetap dikeluarkan sekalipun kegiatan operasi penangkapan tidak dilakukan. Sedangkan biaya variabel adalah biaya yang jumlahnya mengalami perubahan sesuai dengan tingkat produksi yang dilakukan (Heriawan, 2008 mengacu pada Soeharto, 1999). Kriteria kedua yang digunakan adalah biaya usaha. Sama halnya dengan nilai investasi, penentuan prioritas ditentukan berdasarkan nilai biaya terendah yang dikeluarkan oleh suatu unit penangkapan.

3. Keuntungan atau Revenue and cost rasio (R/C), digunakan untuk mengetahui sejauh mana hasil usaha penangkapan dalam priode waktu tertentu cukup menguntungkan atau tidak. Nilai R/C diperoleh dengan cara membandingkan penerimaan yang diperoleh dengan biaya yang dikeluarkan dalam waktu satu tahun, usaha dikatakan untung apabila nilai R/C>1 (Heriawan, 2008 mengacu pada
Soeharto, 1999). Berbeda dengan dua kriteria sebelumnya, nilai prioritas yang didasarkan pada kriteria keuntungan ditentukan berdasarkan nilai keuntungan terbesar. Semakin besar keuntungan maka semakin tinggi prioritas dari suatu alat tangkap. Rumus yang digunakan untuk perhitungan nilai $\mathrm{R} / \mathrm{C}$ ratio adalah:

$$
\frac{R}{C} \text { ratio }=\frac{P q \times Q}{\mathrm{TFC}+\mathrm{TVC}}
$$

Keterangan :

$$
\begin{array}{ll}
\text { Pq } & : \text { Harga Output } \\
\text { Q } & : \text { Output } \\
\text { TFC } & : \text { Total Biaya Tetap } \\
\text { TVC } & : \text { Total Biaya Variabel }
\end{array}
$$

4. Payback periode (PP), merupakan periode waktu yang diperlukan untuk menutup kembali pengeluaran biaya investasi dengan menggunakan aliran kas dalam satu bulan atau satu tahun. Semakin besar nilai payback periode semakin besar prioritas unit penangkapan tersebut. Rumus yang digunakan untuk menghitung PP adalah sebagai berikut (Soeharto 1999):

$$
\text { Payback Periode }=\frac{C f}{\mathrm{~A}}
$$

Keterangan :

$$
\begin{array}{ll}
\text { Cf } & \text { : Biaya Pertama } \\
\text { A } & \text { : Aliran kas bersih (netto) } \\
& \text { pertahun }
\end{array}
$$

5. Analisis rasio biaya dan manfaat $(B / C$ ratio), menurut Heriawan (2008) analisis $B / C$ ratio digunakan untuk menilai kelayakan sebuah investasi yang ditanamkan secara ekonomi maupun finansial. $B / C$ ratio merupakan perbandingan dimana pembilangnya terdiri dari nilai manfaat total yang sudah didiskon dengan tingtak diskon tertentu, sedangkan penyebutnya adalah total biaya yang sudah didiskon. Menurut Ngamel (2012), perbandingan antara tingkat keuntungan yang diperoleh dengan total biaya yang dikeluarkan 
dengan analisa B/C Ratio dapat diketahui dengan rumus:

$$
\frac{B}{C} \text { ratio }=\frac{P V \text { Benefit }}{P V \text { Cost }}
$$

\section{Keterangan :}

PV Benefit: Present value dari total penerimaan

PV cost : Present value dari total biaya

Dari persamaan tersebut di atas, dapat disusun kriteria kelayakan investasi dimana apabila nilai B/C memberikan nilai lebih besar dari 1 maka dikatakan investasi tersebut layak untuk diteruskan. Sebaliknya, apabila nilai B/C tersebut kurang dari 1 maka dikatakan investasi tersebut tidak layak untuk diteruskan (Pratama 2012).

Untuk menentukan teknologi penangkapan ikan yang tepat guna akan dilakukan dengan metode MCA (Multi Criteria Analysis). Indikator bio-ekologi, teknis, ekonomi dan sosial digunakan sebagai indikator untuk menilai keunggulan alat tangkap. Untuk dapat memenuhi prosedur kerja agar dapat mencapai tujuan dari penelitian, maka selanjutnya perlu dilakukan standarisasi untuk masing-masing variabel dalam indikator yang akan dianalisis. Standarisasi tersebut dilakukan dengan menggunakan rumus sebagai berikut (Briguglio 1995):

$$
S V i j=\frac{X i j-M i n X i j}{M a x X i j-M i n X i j}
$$

$0<\mathrm{SV}_{\mathrm{mni}}<1$

\section{Keterangan :}

J : Indikator

I : Jenis alat tangkap

SVi,j : Nilai standarisasi indikator ke-j untuk alat tangkap-i

Xij : Nilai indikator ke-j untuk alat tangkap-i

Min Xij : Nilai minimal dari indikator ke-j untuk alat tangkap-i

Max Xij : Nilai maksimal dari indikator ke-j untuk alat tangkap-i
Untuk membuat indeks komposit dari indikator yang diukur, maka setiap variabel di dalam masing-masing indikator diasumsikan memiliki bobot sama $(\mathrm{w}=1)$ sehingga nilai akhir untuk setiap indikator adalah:

$$
N K i=\frac{\sum_{y-1}^{m} S V y}{m}
$$

Keterangan:

$$
\begin{array}{ll}
\text { NKi } & : \text { Nilai Komposit untuk } \\
& \text { indikator i } \\
S V y & : \text { Nilai standardisasi variable } \\
& \text { ke-y dalam domain ke-i } \\
m & : \text { Jumlah variabel dalam } \\
& \text { domain ke-i }
\end{array}
$$

Tahapan penelitian ini dilakukan untuk menganalisis unit penangkapan ikan yang digunakan oleh armada sampel, agar dapat dipilih satu jenis alat tangkap tepat guna yang sesuai dengan kondisi perairan di Pulau Enggano dilihat dari aspek bio-ekologi, teknis, sosial serta ekonomi (Gambar 2). Pemilihan kriteria pada aspek tersebut didasarkan bahwa kriteria tersebut merupakan faktor yang dominan dalam pengoperasian unit penangkapan ikan di Pulau Enggano. Kriteria tersebut diharapkan akan memberikan pengaruh yang besar terhadap hasil akhir pemilihan unit penangkapan ikan yang tepat guna.

Multi Criteria Analysis digunakan untuk mendukung proses dimana bermacammacam pemangku kepentingan dapat menentukan informasi pada kriteria dan dampak serta mengkaji keluaran dan dampak dari keputusan yang dibuat sebagai hasil dari perbedaan prioritas. Analisis ini dilakukan melalui penerapan bobot berbeda dari kriteria bio-ekologi, teknis, ekonomi, dan sosial. Penggunaan MCA berorientasi pada proses dibandingkan berorientasi hasil, sehingga dapat digunakan sebagai alat untuk memfasilitasi pertimbangan pemangku kepentingan (Brown 2001). 


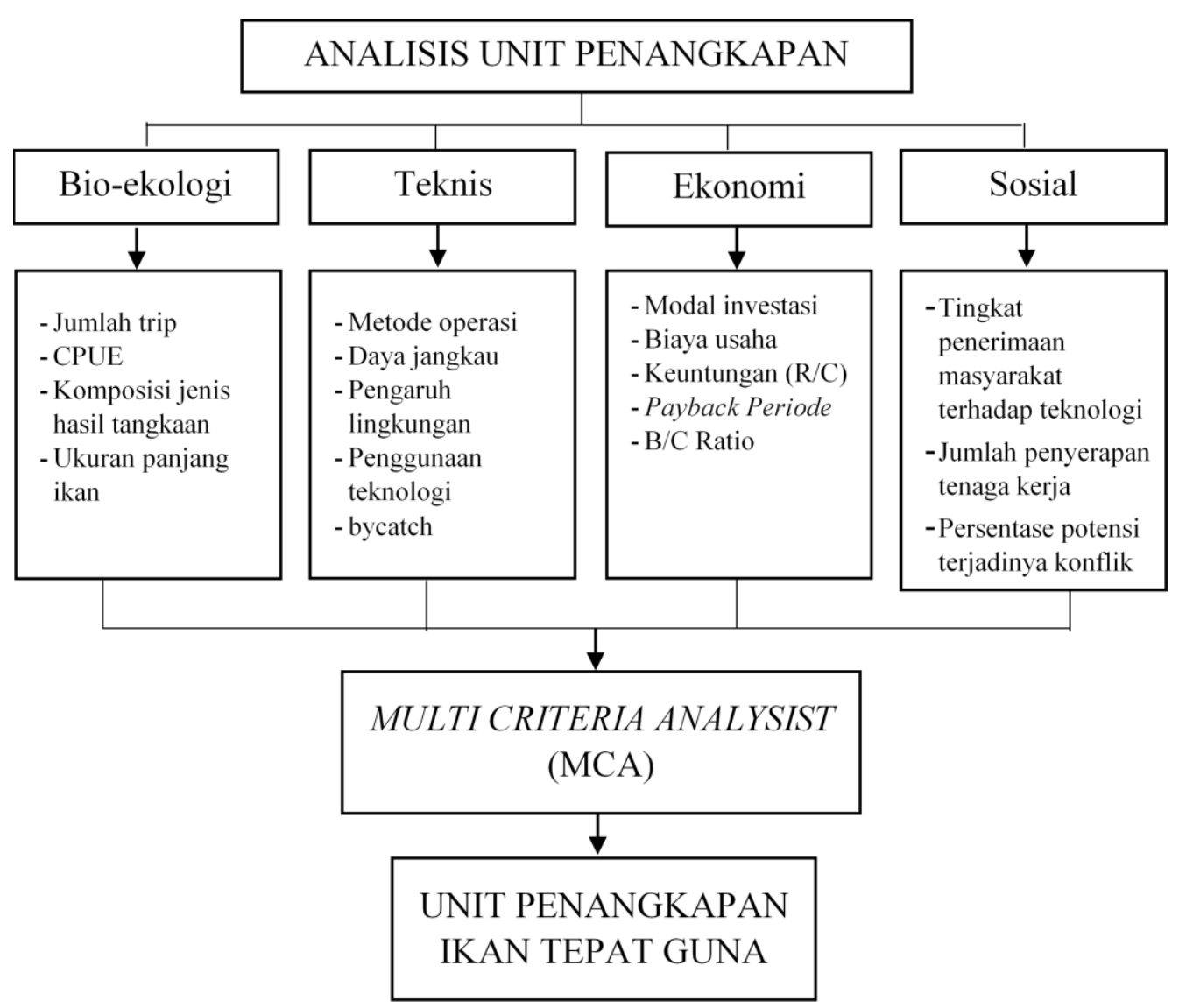

Gambar 1 Diagram alir identifikasi dan analisis unit penangkapan ikan tepat guna

\section{HASIL DAN PEMBAHASAN}

\section{Gillnet}

Nelayan di Desa Kahyapu melakukan penangkapan dengan menggunakan kapal berukukuran 1GT. Panjang kapal hanya berikisar 3-5 meter dan lebar 1,5-2 meter. Kapal yang digunakan di gerakkan oleh mesin motor tempel yang kekuatannya 5-5,5 PK. Ukuran jaring yang biasa digunakan oleh nelayan Desa Kahyapu biasanya bervariasi tergantung keinginan pemilik. Rata-rata ukuran panjang jaring yang digunakan oleh Nelayan Desa Kahyapu $\geq 200$ meter, lebar 2,5 meter s/d 3 meter dan mata jaring dengan diameter 2-2,5 cm. Pelampung tanda yang digunakan terbuat dari karet berwarna putih dengan ukuran diameter $35 \mathrm{~cm}$ dan pelampung jaring terbuat dari gabus (Steorofom) berbentuk memanjang dengan ukuran panjang $5 \mathrm{~cm}$ dan jarak antar pelampung jaring 10-15 $\mathrm{cm}$, sedangkan pemberat terbuat dari timah.
Pengoperasian alat tangkap gillnet dilakukan biasanya one day fishing. Para nelayan umumnya berangkat di pagi hari menjelang siang dan baru kembali sebelum atau selepas magrib. Alat tangkap gillnet dioperasaikan dengan menurunkan terlebih dahulu pelampung tanda, kemudia gillnet diulur secara perlahan kedalam perairan sembari juru mudi mendayung kapal. Biasanya saat setting alat tangkap gillnet mesin motor kapal dimatikan. Setelah setting alat selesai dilakukan, nelayan biasanya beristirahat dan menepi disekitar pondok yang mereka miliki. Setelah dua jam, nelayan akan kembali dan melakukan hauling kemudian ikan-ikan yang tertangkap akan langsung dipisahkan dari jaring dan dimasukkan kedalam box fiber yang berisi es. Dalam satu trip penangkapan biasanya nelayan melakukan 5-6 kali setting dan hauling.

\section{Rawai}

Rawai yang biasa digunakan oleh nelayan di Desa Kahyapu adalah rawai dengan 
ukuran mata pancing nomor 4 sebanyak 50 mata pancing, dengan panjang rawai yaitu 3 kilometer. Rawai tersebut menggunakan tali yang ukurannya lebih besar yaitu tali kasar 1000. Alat tangkap ini di operasikan sebanyak 3 kali dalam 1 trip. Pemasangan rawai (setting) biasa dilakukan pada sore hingga malam hari, kemudian rawai di diamkan selama kurang lebih 12 jam hingga keesokan harinya. Pada pagi hari barulah rawai di angkat (hauling) dan ikan-ikan hasil tangkapan langsung diambil dan dimasukkan kedalam box fiber yang sudah berisi es batu. Kapal yang digunakan juga sama dengan gillnet, yaitu kapal berukuran 1GT dengan panjang kapal berikisar 3-5 meter dan lebar 1,5-2 meter. Kapal yang digunakan di gerakkan oleh mesin motor tempel yang kekuatannya 5-5,5 PK.

\section{Seleksi Unit Penangkapan Ikan Tepat Guna}

Penelitian ini sudah dilakuka dengan melihat empat aspek yang dapat dipertimbangkan sebagai penilaian dalam menyeleksi unit penangkapan ikan yang tepat guna, yaitu:

A. Aspek Biologi
Aspek biologi yang dipehartikan dalam penelitian ini adalah jumlah trip, produktivitas, komposisi jenis hasil tangkapan, dan ukuran panjang ikan yang dominan tertangkap. Hasil dari penelitian ini menunjukkan bahwa prioritas untuk unit penangkap ikan berada pada posisi yang sama. Hal ini dikarenakan Gillnet dan rawai mempunyai jumlah trip yang sama, yaitu 8 trip dalam satu bulan. Trip dilakukan sebelum kapal KMP Pulo Telo datang dari Bengkulu, sehingga pada hari kapal tiba di Pulau Enggano, ikan-ikan hasil tangkapan para nelayan lokal siap di packing dan dikirim ke Bengkulu. Pada setiap minggunya kapal KMP Pulo Telo masuk sebanyak dua kali, yaitu di hari rabu dan sabtu.

Kriteria ke dua adalah nilai produktivitas dari masing-masing alat tangkap. Data yang diperoleh menunjukkan bahwa perhitungan nilai produktivitas dari rawai memiliki prioritas lebih bila dibandingkan dengan produktivitas Gillnet. Nilai produktivitas rawai adalah $190.18 \mathrm{~kg} /$ trip dengan hasil standarisari yaitu 0.64, sedangkan Gillnet

Tabel 4 Penilaian dan hasil standarisasi aspek biologi unit penangkapan ikan tepat guna

\begin{tabular}{lcccccccc}
\hline \multicolumn{1}{c}{ Aspek Biologi } \\
\hline Alat tangkap & W1 & UP1 & W2 & UP2 & W3 & UP3 & W4 & UP4 \\
\hline Gillnet & 8 & 1 & 1.43 & 2 & 4.71 & 2 & 2.00 & 1 \\
\hline Rawai & 8 & 1 & 1.57 & 1 & 3.00 & 1 & 1.86 & 2 \\
\hline \multicolumn{8}{c}{ Hasil Standarisasi } \\
\hline Alat tangkap & W1 & W2 & W3 & W4 & Total & rata-rata & UP \\
\hline Gillnet & 1 & 0.48 & 0.57 & 1.00 & 3.05 & 0.76 & 2 \\
\hline Rawai & 1 & 0.64 & 0.67 & 0.86 & 3.16 & 0.79 & 1 \\
\hline
\end{tabular}

\footnotetext{
Keterangan:

W1 : Jumlah trip

W2 : Nilai Produktivitas/trip

W3 : Komposisi hasil tangkapan (jumlah jenis)

W4 : Ukuran ikan yang tertangkap (skor)

UP : Urutan prioritas

$\mathrm{V}$ (W1) : Jumlah trip yang di standarisasi dengan fungsi nilai

$\mathrm{V}(\mathrm{W} 2)$ : Nilai Produktivitas yang di standarisasi dengan fungsi nilai

V (W3) : Komposisi hasil tangkapan yang di standarisasi dengan fungsi nilai

V(W4) : Ukuran ikan yang tertangkap yang di standarisasi dengan fungsi nilai
} 
nilai produktivitasnya adalah $171.15 \mathrm{~kg} /$ trip dengan hasil standarisasi yaitu 0.48 .

Kriteria ke tiga adalah komposisi jenis hasil tangkapan. Kriteria ini dinilai dari hasil pengamatan secara langsung terhadap setiap sampel armada pada setiap alat tangkap (Gillnet dan rawai). Alat tangkap Gillnet memiliki nilai rata-rata jenis hasil tangkapan sebesar 4.71 sedangkan rawai adalah 3.00 artinya adalah alat tangkap Gillnet menangkap lebih banyak jenis ikan dalam satu trip bila dibandingkan dengan rawai yang hanya menangkap satu hingga 3-4 jenis dalam satu trip.

Berdasarkan hasil penelitian, ikan ikan yang tertangkap dengan alat tangkap Gillnet adalah ikan merang atau baronang (Siganus vermiculatus), ikan cabe-cabe (Siganus canaliculatus), ikan jolong-jolong (Tylosurus crocodilus), ikan jompol (Crenimugil crenilabis), ikan bayam-bayam (Chlorurus bleekeri), ikan nawi merah atau kakap merah (Lutjanus argentimaculatus). Sedangkan ikan yang tertangkap oleh rawai adalah ikan arau biru (Caranx melampygus), kakap merah (Lutjanus argentimaculatus), ikan lencam (Lethrinus nebulosus), ikan arau putih (Caranx ignobilis), ikan kerapu nenas (Variola louti), ikan kerapu tikus (Epinephelus corallicola), ikan jenihin atau bibir kuning (Plectorhinchus vittatus), dan ikan nawi kuning atau kakap kuning (Lutjanus rivulatus). Sehingga prioritas utama dalam seleksi unit penangkapan ikan dari kriteria ini adalah rawai.

Kriteria terakhir adalah ukuran panjang ikan yang tertangkap. Urutan prioritas utama adalah Gillnet, sebab hasil penelitian menunjukkan bahwa ukuran-ukuran ikan yang tertangkap dengan menggunakan Gillnet di dominasi oleh ikan-ikan yang lebih besar dari ukuran Lm. Hasil analisis dapat dilihat pada Tabel 4.

\section{B. Aspek Teknis}

Kriteria yang diperhatikan dalam aspek ini di titik beratkan kedalam enam kriteria, yaitu metode pengoperasian alat tangkap, pengaruh pengoperasian alat tangkap terhadap lingkungan, hasil tangkapan terhadap bahan bakar, jalur penangkapan ikan, tingkat penggunaan teknologi, dan bycatch. Hasil penelitian untuk kriteria pertama adalah Gillnet dan rawai mempunya urutan prioritas yang sama, sebab keduanya memiliki nilai hasil standarisasi yang sama yaitu 1 . Artinya kriteria ini memiliki nilai maksimal sehingga pantas untuk mendapatkan urutan prioritas pertama. Sama dengan kriteria pertama, kriteria kedua yaitu pengaruh pengoperasian alat tangkap terhadap lingkungan juga memiliki urutan prioritas yang sama dengan nilai standarisasi maksimal yaitu 1. Alat tangkap Gillnet dan rawai tidak memberikan dampak yang buruk terhadap lingkungan di sekitar pengoperasian alat tangkap, sebab tidak menggerus dasar perairan juga tidak merusak ekosistem karang dan lainnya.

Untuk kriteria ketiga, yaitu hasil tangkapan terhadap bahan bakar urutan prioritasnya adalah rawai. Hal ini dikarenakan dalam beberapa trip terkadang hasil tangkapan Gillnet tidak begitu banyak sehingga tidak menutupi modal bahan bakar. Hasil skor ratarata kriteria ini untuk alat tangkap Gillnet adalah 1.93 sedangkan rawai 2. Hasil standarisasi analisis MCA juga menunjukkan perbedaan yang tipis, yaitu 0.92 untuk Gillnet dan 1 untuk rawai.

Jalur penangkapan dalam aspek teknis menjadi kriteria ke-empat. Hasil analisis skoring dan standarisasi untuk analisis MCA menunjukkan bahwa keduanya memiliki prioritas yang sama dengan nilai maksimal yaitu 1. Hal ini dikarenakan alat tangkap Gillnet dan rawai beroperasi pada jalur penangkapan yang tepat. Jalur penangkapan sesuai dengan PERMEN 02 Tahun 2011 tentang jalur penangkapan ikan dan alat bantu penangkapan ikan.

Ada yang berbeda pada kriteria ke-lima, yaitu keduanya (Gillnet dan rawai) tidak berada pada prioritas utama melainkan prioritas ke-dua. Penyebabnya adalah kedua unit penangkapan ikan ini (Gillnet dan rawai) masih sangat sederhana, sehingga teknologi yang digunakan masih jauh dari kategori "teknologi tinggi". Mesin yang digunakan oleh keduanya adalah mesin 5.5 PK sedangkan di dalam penelitian ini akan dikatakan teknologi 
Tabel 5 Penilaian dan hasil standarisasi aspek teknis unit penangkapan ikan tepat guna

\begin{tabular}{lcccccccccccc}
\hline \multicolumn{10}{c}{ Aspek Teknis } \\
\hline Alat tangkap & X1 & UP1 & X2 & UP2 & X3 & UP3 & X4 & UP4 & X5 & UP5 & X6 & UP6 \\
\hline Gillnet & 2 & 1 & 2 & 1 & 1.93 & 2 & 2 & 1 & 1 & 2 & 1.86 & 2 \\
\hline Rawai & 2 & 1 & 2 & 1 & 2 & 1 & 2 & 1 & 1 & 2 & 2 & 1 \\
\hline \multicolumn{10}{c}{ Hasil Standarisasi } \\
\hline Alat tangkap & $\mathrm{V}(\mathrm{X} 1)$ & $\mathrm{V}(\mathrm{X} 2)$ & $\mathrm{V}(\mathrm{X} 3)$ & $\mathrm{V}(\mathrm{X} 4)$ & $\mathrm{V}(\mathrm{X} 5)$ & $\mathrm{V}(\mathrm{X} 6)$ & total & rata-rata & UP \\
\hline Gillnet & 1 & 1 & 0.92 & 1 & 0 & 0.86 & 4.79 & 0.80 & 2 \\
\hline Rawai & 1 & 1 & 1 & 1 & 0 & 1 & 5 & 0.83 & 1 \\
\hline
\end{tabular}

Keterangan:

X1 : Metode pengoperasian alat tangkap (skor)

X2 : Pengaruh pengoperasian alat tangkap (skor)

X3 : Hasil tangkapan terhadap bahan bakar (skor)

X4 : Jalur penangkapan ikan (skor)

X5 : Tingkat penggunaan teknologi (skor)

X6 : Bycatch

UP : Urutan prioritas

$\mathrm{V}(\mathrm{X} 1)$ : Metode pengoperasian alat tangkap yang di standarisasi dengan fungsi nilai

$\mathrm{V}(\mathrm{X} 2)$ : Pengaruh pengoperasian alat tangkap yang di standarisasi dengan fungsi nilai

$\mathrm{V}(\mathrm{X} 3)$ : Hasil tangkapan terhadap bahan bakar yang di standarisasi dengan fungsi nilai

$\mathrm{V}(\mathrm{X} 4)$ : Jalur penangkapan ikan yang di standarisasi dengan fungsi nilai

$\mathrm{V}(\mathrm{X} 5)$ : Tingkat penggunaan teknologi yang di standarisasi dengan fungsi nilai

$\mathrm{V}(\mathrm{X} 6)$ : Bycatch yang di standarisasi dengan fungsi nilai

tinggi apabila mesin yang digunakan lebih besar dari $15 \mathrm{PK}$.

Terakhir adalah kriteria ke-enam yaitu bycatch. Rawai menjadi lebih unggul sebab dalam hasil wawancara dan survey menunjukkan bahwa bycatch yang diperoleh rawai adalah rendah, sehingga responden memberikan skor 2. Sedangkan Gillnet menjadi tidak maksimal skornya oleh karena beberapa responden memberikan skor 1 . Hal ini memang karena dalam pengoperasian alat tangkap Gillnet ada beberapa yang hasil tangkapannya tidak sesuai dengan hasil tangkapan target.

Secara keseluruhan, analisis MCA yang telah dilakukan untuk aspek teknis memberikan urutan prioritas yang utama untuk alat tangkap rawai, dengan selisih nilai 0.3 dengan alat tangkap Gillnet, nilai rata-rata rawai adalah 0.83 dan Gillnet adalah 0.80. Hasil analisis dapat dilihat pada Tabel 5 .

C. Aspek Sosial
Adapun kriteria yang dinilai dari aspek sosial adalah kriteria tingkat penerimaan masyarakat terhadap alat tangkap yang digunakan, penyerapan tenaga kerja, dan kemungkinan menimbulkan konflik antar nelayan alat tangkap yang berbeda. Kriteria pertama, tingkat penerimaan teknologi dinilai dengan hasil skoring yang diperoleh dari hasil wawancara terhadap responden. Untuk kriteria pertama, nelayan Gillnet dan rawai mempunyai nilai rata-rata skor yang sama yaitu 2. Hal ini berarti secara menyeluruh alat tangkap yang digunakan mampu diterima dengan baik oleh masyarakat setempat. Di lokasi penelitian yaitu Desa Kahyapu, ada dua kelompok nelayan yaitu kelompok nelayan Gillnet dan rawai. Setiap anggota kelompok dikepalai oleh masing-masing satu orang yang mempunyai kapal sekaligus menjadi pengepul ikan. Nelayan Gillnet beranggotakan 30 orang dengan jumlah armada sebanyak 15 unit kapal dengan mesin motor tempel. Nelayan rawai beranggotakan 27 orang dengan unit armada 
Tabel 6 Penilaian dan hasil standarisasi aspek sosial unit penangkapan ikan tepat guna

\begin{tabular}{lcccccc}
\hline \multicolumn{7}{c}{ Aspek Sosial } \\
\hline Alat tangkap & Y1 & UP1 & Y2 & UP2 & Y3 & UP3 \\
\hline Gillnet & 2 & 1 & 1.57 & 2 & 2 & 1 \\
\hline Rawai & 2 & 1 & 1.79 & 1 & 2 & 1 \\
\hline \multicolumn{7}{c}{ Hasil Standarisasi } \\
\hline Alat tangkap & $\mathrm{V}(\mathrm{Y} 1)$ & $\mathrm{V}(\mathrm{Y} 2)$ & $\mathrm{V}(\mathrm{Y} 3)$ & total & rata-rata & $\mathrm{UP}$ \\
\hline Gillnet & 1 & 0.57 & 1 & 2.57 & 0.86 & 2 \\
\hline Rawai & 1 & 0.79 & 1 & 2.79 & 0.93 & 1 \\
\hline
\end{tabular}

Keterangan:

Y1 : Penerimaan masyarakat terhadap alat tangkap yang digunakan (skor)

Y2 : Penyerapan tenaga kerja (skor)

Y3 : Potensi konflik (skor)

UP : Urutan prioritas

V(Y1) : Penerimaan masyarakat terhadap alat tangkap yang digunakan yang di standarisasi dengan nilai fungsi

V(Y2) : Penyerapan tenaga kerja yang di standarisasi dengan nilai fungsi

V(Y3) : Potensi konflik yang di standarisasi dengan nilai fungsi

sebanyak 14 kapal dengan mesin motor tempel.

Dari penjelasan tersebut dapat diketahui bahwa persentase penerimaan masyarakat terhadap alat tersebut adalah jelas lebih dari $60 \%$ sehingga masuk ke dalam kategori tinggi. Singkatnya, urutan prioritas kedua alat tangkap tersebut adalah sama, yaitu 1.

Kriteria ke-dua adalah jumlah penyerapan tenaga kerja. Rawai menduduki prioritas utama, sebab dalam wawancara yang dilakukan hampir $78 \%$ responden menyatakan bahwa mereka membutuhkan anggota tambahan untuk melakukan operasi penangkapan ikan. Hal ini disebabkan setiap kapal rata-rata hanya beranggotakan dua orang nelayan saja yang berangkat beroperasi, sehingga terkadang terasa sulit untuk melakukan setting dan hauling karena hanya satu orang saja yang melakukannya, sedangkan abk lain mengemudi armada. Hasil standarisasi analisis MCA menunjukkan bahwa rawai memiliki nilai 0.79 sedangkan Gillnet 0.57 .

Kriteria terakhir adalah persentase terjadinya konflik, kedua alat tangkap memiliki nilai standarisasi analisis MCA yang maksimal, yaitu 1. Artinya, kedua alat tangkap tidak berpeluang menimbulkan konflik, sebab daerah penangkapan ikan yang dilakukan oleh kedua alat tangkap tersebut tidak saling mengganggu, apalagi saling merugikan. Hasil analisis data disajikan pada Tabel 6.

\section{Aspek Ekonomi}

Aspek ekonomi dianalisis dengan memperhatikan beberapa kriteria, yaitu modal (investasi), biaya usaha, keuntungan (R/C ratio), dan $\mathrm{B} / \mathrm{C}$ ratio. Tujuan yang ingin dicapai dengan melakukan analisis tersebut adalah supaya nelayan lokal mampu memilih unit penangkapan ikan yang memberikan keuntungan lebih besar dengan modal usaha (investasi) lebih kecil. Kriteria pertama yaitu modal (investasi), Gillnet menjadi lebih unggul bila dibandingkan dengan alat tangkap rawai. Hal ini disebabkan oleh modal investasi rawai ternyata lebih tinggi sebesar Rp 13650000,sedangkan Gillnet modal investasinya sebesar 13285714.

Kriteria ke dua adalah biaya usaha. Biaya udaha merupakan biaya yang dikeluarkan dalam setiap trip penangkapan. Unit penangkap ikan dengan alat tangkap 
Tabel 6 Penilaian dan hasil standarisasi aspek ekonomi unit penangkapan ikan tepat guna

\begin{tabular}{lcccccccccc}
\hline \multicolumn{10}{c}{ Aspek Ekonomi } \\
\hline Alat tangkap & Z1 & UP1 & Z2 & UP2 & Z3 & UP3 & Z4 & UP4 & Z5 & UP5 \\
\hline Gillnet & 13285714.29 & 1 & 70920000 & 1 & 2.36 & 2 & 0.14 & 1 & 1.16 & 2 \\
\hline Rawai & 13650000 & 2 & 91940000 & 2 & 4.52 & 1 & 0.04 & 2 & 3.36 & 1 \\
\hline \multicolumn{10}{c}{ Hasil Standarisasi } \\
\hline Alat tangkap & Z1 & Z2 & Z3 & Z4 & Z5 & total & rata-rata & UP & \\
\hline Gillnet & 0.14 & 0.60 & 0.33 & 0.30 & 0.34 & 1.72 & 0.34 & 2 & \\
\hline Rawai & 0.45 & 0.57 & 0.51 & 0.39 & 0.51 & 2.44 & 0.49 & 1 & \\
\hline
\end{tabular}

Keterangan:

Z1 : Modal investasi

Z2 : Biaya usaha

Z3 : Keuntungan R/C Ratio

Z4 : Payback Periode

Z5 : B/C Ratio

UP : Urutan prioritas

$\mathrm{V}(\mathrm{Z1})$ : Modal investasi yang di standarisasi dengan fungsi nilai

$\mathrm{V}(\mathrm{Z2})$ : Biaya usaha yang di standarisasi dengan fungsi nilai

$\mathrm{V}(\mathrm{Z3})$ : Keuntungan R/C Ratio yang di standarisasi dengan fungsi nilai

$\mathrm{V}(\mathrm{Z} 4)$ : Payback Periode yang di standarisasi dengan fungsi nilai

$\mathrm{V}(\mathrm{Z5})$ : B/C Ratio vang di standarisasi dengan fungsi nilai

rawai lebih besar bila dibanding dengan Gillnet, yaitu 91940000 rupiah. Namun sebenarnya alat tangkap rawai ini waktu beroperasinya lebih lama bila dibandingkan dengan Gillnet. Penyebabnya adalah daerah penangkapan rawai cenderung lebih jauh bila dibandingkan dengan Gillnet, sehingga biaya perbekalan dan bahan bakar menjadi lebih besar.

Kriteria ke-tiga adalah keuntungan (R/C ratio), dalam segi keuntungan unit penangkapan ikan dengan alat tangkap rawai lebih besar bila dibandingkan dengan Gillnet. Penyebabnya adalah hasil tangkap rawai jauh lebih bernilai ekonomis daripada hasil tangkapan Gillnet. setidaknya ikan-ikan hasil tangkapan rawai adalah ikan-ikan besar yang di hargai 17000-18000 per kg, sedangkan ikanikan hasil tangkapan Gillnet adalah ikan-ikan yang harganya 5000-10000 per kg.

Kriteria ke-empat adalah payback periode, kriteria ini dimaksudkan untuk melihat kemampuan pengembalian modal yang dikeluarkan dalam jangka waktu tertentu sehingga usaha dapat melakukan penambahan investasi bila memungkinkan. Urutan prioritas dimiliki oleh rawai dengan nilai standarisasi 0.39 , sedangkan gillnet nilai standarisasinya adalah 0.30 .

Kriteria ke-lima adalah B/C ratio, yaitu rasio antara keutungan dan biaya. Kriteria B/C ratio adalah perbandingan antara seluruh nilai kini keuntungan yang didapat dengan seluruh nilai kini biaya yang dikeluarkan. Bila nilai $\mathrm{B} / \mathrm{C}$ ratio lebih kecil dari satu maka usaha mengalami kerugian, jika nilai $\mathrm{B} / \mathrm{C}$ ratio sama dengan satu maka usaha dalam kondisi break event point dan bila $\mathrm{B} / \mathrm{C}$ ratio lebih besar dari satu maka usaha mengalami keuntungan. Semakin besar nilai B/C ratio semakin besar keuntungan usaha yang didapat (Gittinger, 1986)

Hasil analisis B/C Ratio untuk alat tangkap rawai memiliki nilai 3.36 sedangkan Gillnet 1.16. Berdasarkan pernyataan Gittinger (1986) secara finansial usaha perikanan tangkap dengan alat tangkap rawai dan alat tangkap Gillnet layak untuk dilakukan. 


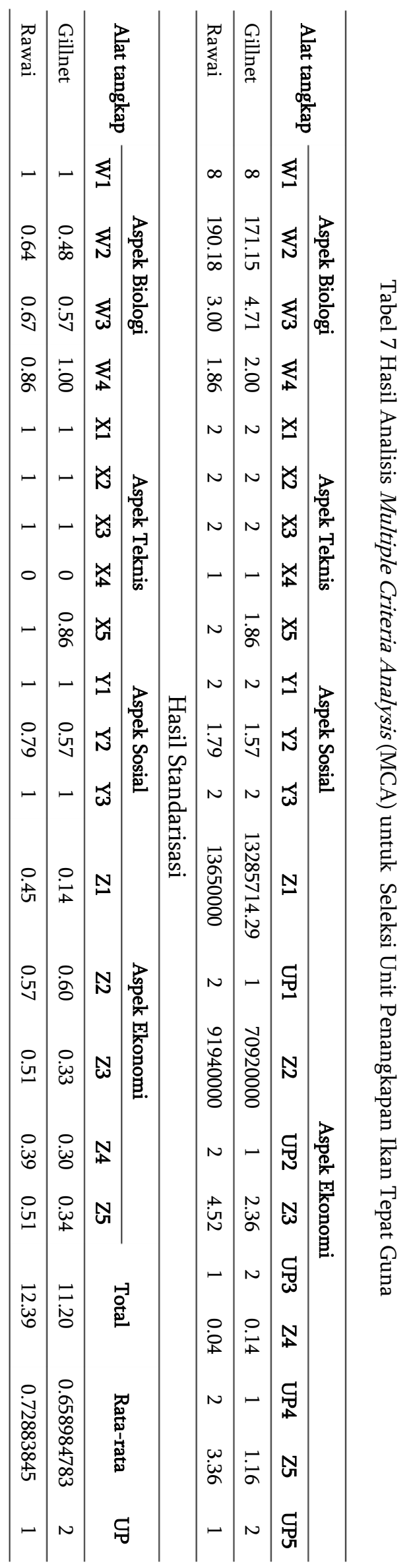


Hal yang membedakan antara analisis B/C Ratio dan R/C Ratio adalah variabel yang digunakan. Bila analisis $\mathrm{R} / \mathrm{C}$ Ratio menggunakan nilai rasio penerimaan dan biaya, maka B/C Ratio menggunakan variabel yang membandingkan antara nilai sekarang dari penerimaan atau pendapatan yang diperoleh dari ivestasi dengan nilai sekarang dari pengeluaran (biaya) selama investasi tersebut berlangsung dalam kurun waktu tertentu.

Secara keseluruhan aspek ekonomi, unit penangkapan ikan yang prioritas utama adalah rawai dengan nilai standarisasi analisis MCA sebesar 0.51 dan prioritas ke-dua adalah Gillnet dengan nilai 0.35 . Hasil analisis dapat dilihat pada Tabel 7.

Seleksi unit penangkapan ikan yang tepat guna, dilakukan dengan menggunakan Multiple Criteria Analysis (MCA), analisis ini dilakukan dengan melakukan standarisasi terhadap setiap kriteria dalam empat aspek yang diamati. Hasil dari Multiple Criteria Analysis (MCA) yang sudah dilakukan pada penelitian ini disajikan pada Tabel 8.

Dari tabel di atas, dapat diihat bahwa semua aspek sudah memiliki nilai dengan satuan dan tipe yang sama. Standarisasi di dalam Multiple Criteria Analysis (MCA) ini memang dirancang agar pethitungan serta analisisnya menjadi lebih mudah untuk dilakukan meskipun setiap aspek satuannya berbeda. Dengan analisis Multiple Criteria Analysis (MCA), standarisasi menjadikan semua output data dalam satuan yang sama.

Hasil analisis yang telah dilakukan sebelumnya telah dibahas secara rinci peraspek, namun pada bagian ini akan dibahas secara menyeluruh agar dapat dilihat hasilnya secara utuh. Rawai berada pada urutan prioritas utama dengan nilai rata-rata dari seluruh aspek adalah 0.75 sedangkan Gillnet berada pada urutan prioritas ke-dua dengan nilai rata-rata 0.63 . Hal ini menunjukkan bahwa rawai lebih unggul dan tepat guna dalam semua aspek.

\section{KESIMPULAN}

Urutan proiritas pertama untuk alat tangkap yang tepat guna adalah rawai, kemudian gillnet. Dari aspek ekonomi alat tangkap rawai memiliki nilai $\mathrm{R} / \mathrm{C}$ ratio sebesar 0,51 dan 0,33 untuk alat tangkap gillnet. bila dilihat dari nilai $\mathrm{B} / \mathrm{C}$ rationya, alat tangkap rawai adalah 0,49 sedangkan gillnet adalah 0,34 .

\section{DAFTAR PUSTAKA}

Arikunto S. 2002. Metodologi penelitian. Jakarta (ID): PT. Rineka Cipta.

Brown K. 2001. Analysis Trade-off analysis for marine protected area management. Journal of Marine Policy. 417-434.

Briguglio L. 1995. Small island states and their economics vulnerabilities. World Development, 23. hlm $1615-1632$.

Dahlan A. 2015. Definisi sampling serta jenis metode dan teknik sampling. Eureka Pendidikan [Internet]. [diunduh $2016 \quad$ Feb 13]. Tersedia pada: http://www.eurekapendidikan.com/2015/09/defenisi-sampling-dan-teknik-sampling.html

Dinas Kelautan Dan Perikanan Bengkulu Utara. 2013. Pengembangan Database KP3K Kabupaten Bengkulu Utara.

Heriawan Y. 2008. Alokasi unit penangkapan ikan pelagis kecil di Perairan Pandeglang, Banten: menuju perikanan tangkap yang terkendali. [tesis]. Bogor (ID): Institut Pertanian Bogor.

Gittinger, JP. 1986. Analisis Ekonomi Proyek-Proyek Pertanian. UI Press-John Hopkins, Jakarta.

Nazir. 2003. Metode Penelitian. Jakarta (ID): Salemba Empat, hal 63. 
Ngamel AK. 2012. Analisis finansial usaha budidaya rumput laut dan nilai tambah tepung karaginan di Kecamatan Kei Kecil, Kabupaten Maluku Tenggara. Jurnal Sains Terapan, 2(1), 68-83.

Pratama F, Boesono H, Hapsari T. 2012. Analisis kelayakan finansial usaha penangkapan ikan menggunakan panah dan bubu dasar di Perairan Karimunjawa. Journal of Fisheries Resources Utilization Management and Technology, 1(1), 22-31.

Simbolon D. 2004. Suatu studi tentang potensi pengembangan sumberdaya ikan cakalang dan teknologi penangkapan yang ramah lingkungan. Buletin PSP. Bogor (ID): Departemen Pemanfaatan Sumberdaya Perikanan, Fakultas Perikanan dan Ilmu Kelautan, Institut Pertanian Bogor. 13(1): 48- 67.

Suwarni. 2009. Hubungan panjang-bobot dan faktor kondisi ikan Butanan Acanthurus mata (Cuvier, 1829) yang tertangkap di sekitar perairan Pantai Desa Mattiro Deceng, Kabupaten Pangkajene Kepulauan, Provinsi Sulawesi Selatan. Jurnal Ilmu Kelautan dan Perikanan. 19(3): 160- 165.

Wujdi A, Suwarso, Wudianto. 2013. Hubungan panjang bobot, faktor kondisi dan struktur ukuran ikan Lemuru di perairan. 